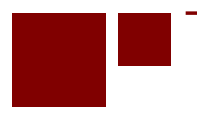

C E N T E R for RETIREMENT RE S E A R C H at BOSTON COLLEGE

\title{
DEMENTIA, HELP WITH FINANCIAL MANAGEMENT, AND WELL-BEING
}

\author{
Anek Belbase and Geoffrey T. Sanzenbacher
}

CRR WP 2017-11

September 2017

\author{
Center for Retirement Research at Boston College \\ Hovey House \\ 140 Commonwealth Avenue \\ Chestnut Hill, MA 02467
}

Tel: 617-552-1762 Fax: 617-552-0191

http://crr.bc.edu

Both authors are with the Center for Retirement Research at Boston College. Anek Belbase is a research fellow and Geoffrey T. Sanzenbacher is a research economist. The research reported herein was performed pursuant to a grant from the U.S. Social Security Administration (SSA) funded as part of the Retirement Research Consortium. The opinions and conclusions expressed are solely those of the authors and do not represent the opinions or policy of SSA, any agency of the federal government, or Boston College. Neither the United States Government nor any agency thereof, nor any of their employees, makes any warranty, express or implied, or assumes any legal liability or responsibility for the accuracy, completeness, or usefulness of the contents of this report. Reference herein to any specific commercial product, process or service by trade name, trademark, manufacturer, or otherwise does not necessarily constitute or imply endorsement, recommendation or favoring by the United States Government or any agency thereof.

(C) 2017, Anek Belbase and Geoffrey T. Sanzenbacher. All rights reserved. Short sections of text, not to exceed two paragraphs, may be quoted without explicit permission provided that full credit, including $@$ notice, is given to the source. 


\begin{abstract}
About the Center for Retirement Research
The Center for Retirement Research at Boston College, part of a consortium that includes parallel centers at the University of Michigan and the National Bureau of Economic Research, was established in 1998 through a grant from the Social Security Administration. The Center's mission is to produce first-class research and forge a strong link between the academic community and decision-makers in the public and private sectors around an issue of critical importance to the nation's future. To achieve this mission, the Center sponsors a wide variety of research projects, transmits new findings to a broad audience, trains new scholars, and broadens access to valuable data sources.
\end{abstract}

Center for Retirement Research at Boston College

Hovey House

140 Commonwealth Ave

Chestnut Hill, MA 02467

Tel: 617-552-1762 Fax: 617-552-0191

http://crr.bc.edu

Affiliated Institutions:

The Brookings Institution

Syracuse University

Urban Institute 


\begin{abstract}
Earlier research indicated that the vast majority of retirees with dementia do not use the U.S. Social Security Administration's Representative Payee Program, despite the fact that many have lost the capacity to manage their own finances. However, that research also indicated that most retirees with dementia do have access to informal caregivers who could assist them (e.g., a resident adult child or non-impaired spouse), but the research did not examine whether those individuals provided assistance specifically with financial management. This paper uses the National Health and Aging Trends Study to determine whether beneficiaries with dementia receive help from their informal caregivers in managing their finances. The paper also examines the financial well-being of those with assistance compared to those without assistance.
\end{abstract}

This paper found that:

- Over 85 percent of individuals with dementia receive informal help with simple banking matters like paying bills, as well as complex matters like managing retirement accounts.

- Those with dementia who receive help are indistinguishable from those without dementia in terms of any difficulties they experience paying for utilities, rent, medicine, and food.

- The minority of adults who have dementia but do not receive help managing their money are more likely to experience difficulty paying for necessities.

- The apparent benefits of informal help is robust to controls for socioeconomic factors like race, education, and income.

The policy implications of this paper are:

- One reason the Representative Payee Program may be used infrequently by those with dementia is that they have informal sources of assistance with their finances.

- Because that assistance is generally successful in preventing financial distress, families may feel the need to utilize the program only as a last resort. 


\section{Introduction}

The human life cycle starts and ends with dependence. The growing pains associated with becoming a self-sufficient adult are well documented. But as people grow old and lose physical and mental capacity, they often face a difficult transition from that hard won selfsufficiency to dependence. For older adults who develop dementia, this loss of capacity is particularly severe and drawn-out: people can live a decade or more with dementia but will need help with a wide range of routine activities, such as cooking and dressing, as the disease progresses. The ultimate result is that people with dementia often lose their autonomy as caregivers step in to prevent them from hurting themselves or others. Unlike children, who are legally required to have a guardian make important decisions on their behalf, dementia patients are not required to give up their independence and may be slow to relinquish control of their affairs. As a result, control over decisions must be negotiated within families or, in extreme cases, decided in a court of law.

One particularly difficult transition that adults with dementia and their caregivers must navigate is relinquishing control over financial decisions. Indeed, an early sign of dementia is difficulty managing one's finances, and within a few years of developing dementia, most people lose the capacity to manage their money in their own best interest. ${ }^{1}$ Yet, they are often unaware of their impaired judgment and resist giving up control. ${ }^{2}$ People in the early stages of dementia are susceptible to fraud and likely to make financial mistakes. ${ }^{3}$ As dementia progresses and they become increasingly dependent on caregivers to carry out everyday activities, the risk of financial abuse increases. ${ }^{4}$

To prevent financial exploitation, Social Security allows beneficiaries who cannot manage their own benefits to turn over control of them to a representative payee. Once designated, a representative payee is required to decide how to spend a beneficiary’s Social Security income and keep records of that spending to prove the benefits were spent appropriately. Most of the 5.5 million people participating in the Social Security Administration's (SSA) Representative Payee Program are children - who require a legal guardian - or disabled adults. ${ }^{5}$ However, a little over half-a-million retirement beneficiaries

\footnotetext{
${ }^{1}$ See Widera et al. (2011) for a good review of the literature.

${ }^{2}$ Hsu and Willis (2013).

3 Triebel et al., (2009); Martin et al. (2003).

${ }^{4}$ New York City Department of Aging (2011).

${ }^{5}$ Over 3 million SSI recipients also have representative payees.
} 
have representative payees. While this number may seem large, it represents less than 2 percent of the 65-and-older population, even though over 10 percent of them have dementia. ${ }^{6}$ This imbalance is reflected in a recent study by Belbase and Sanzenbacher (2016) that finds just over 9 percent of retirees with dementia have representative payees. As a result, some studies have suggested that SSA should cover more retirees under its Representative Payee Program. ${ }^{7}$

But to some observers, the program is striking the correct balance between maintaining the autonomy of beneficiaries and ensuring that their payments are spent in their best interests. The reason for the disagreement over whether the program is underutilized stems from the unique problem posed by dementia. Some individuals with dementia can still receive and manage their own benefit, while others cannot. ${ }^{8}$ Although almost all people with common forms of dementia will eventually lose the ability to manage their finances, caregivers initially can be involved in joint decisions before permanently "taking the keys away” as impairment becomes more severe. So the difference between those who need payees and those who do not often comes down to the quality of each individual's informal care network - which Social Security cannot observe. Simply assuming those with dementia need a payee risks taking away someone's independence prematurely. ${ }^{9}$

Indeed, recent research suggests that Social Security beneficiaries with dementia have access to potential sources of help, perhaps limiting the need for representative payees. Belbase and Sanzenbacher (2016) find that 95 percent of beneficiaries with dementia either have a representative payee, have a non-impaired spouse or child, have given someone power of attorney, or live in a nursing home where they often do not need to manage finances. In other words, despite the fact that payee use is uncommon, very few individuals with dementia are living in the community without any form of assistance. At the same time, the data used in the 2016 study did not include complete information on whether the informal care network specifically provided assistance with financial management. ${ }^{10}$ To date, it is not known to what

\footnotetext{
${ }^{6}$ Anguelov, Ravida, and Weathers II (2015); Herbert et al. (2013).

${ }^{7}$ For example, a 2010 audit by the Office of the Inspector General found retirees over the age of 85 in need of a payee, and some experts have argued that the process used by field offices to determine financial capacity errs on the side of finding someone capable rather than incapable.

${ }^{8}$ Widera et al. (2011).

${ }^{9}$ Barry, Brandon, Apesoa-Varano, and Gomez (2015).

${ }^{10}$ The Health and Retirement Study used in this earlier research asks about help with the IADL related to financial management but only if individuals indicated they needed help. Since some individuals may be receiving help but also claim they do not need it, it is unclear this line of questioning provides complete information on coverage.
} 
extent these sources of help actually assist in managing the finances of those with dementia, and whether this help prevents financial misuse or abuse.

This project fills this gap in the literature by examining the role of informal caregivers in helping beneficiaries with dementia manage their financial affairs using a relatively new dataset, the National Health and Aging Trends Study (NHATS). In particular, the study examines whether retirees' informal care networks provide help with simple financial matters like bill paying and complex matters like managing retirement accounts as they transition from normal cognition to potential dementia and ultimately to having established dementia for three or more consecutive years. The project also examines the extent to which having this help improves retirees' financial well-being and the extent to which those without help suffer negative consequences.

The results suggest that over 85 percent of those with established dementia receive help both with simple banking matters and with more complicated money matters (if they have complicated financial matters to deal with). Those receiving help with their finances appear to be as financially well off as those without dementia, as measured by problems affording food, rent, utility payments, and medical bills. This finding persists even when controlling for socioeconomic factors likely correlated with both having help available and with financial wellbeing (e.g., education, race). On the other hand, the 15 percent of those with established dementia who do not have help with their financial management are twice as likely as those with no cognitive impairment to have difficulty making ends meet. This result supports the notion that informal help has a positive impact on financial well-being - despite the risk that the informal helpers may not be financially savvy or could engage in neglect or abuse.

The remainder of the paper is organized as follows. The second section describes the data and empirical approach and the third section reports results. The final section concludes that the NHATS data suggest that one reason many retirees do not utilize the representative payee program is that they have help with financial management from their informal care networks. However, as the baby boom generation approaches old age, it is still worth considering how best to provide help to those that do not yet have it. 


\section{Data and Empirical Strategy}

The NHATS is a nationally representative sample of Medicare beneficiaries ages 65 and older. Since 2011, the NHATS has conducted annual, in-person interviews to capture trends in late-life functioning. The dataset provides a comprehensive view of how older adults adapt to the changes associated with aging by capturing variables on their economic and psychological well-being, difficulty carrying out daily activities, and help or accommodations made to carry out those activities. This paper uses NHATS data from 2011-2014, during which a total of 8,245 people were interviewed. ${ }^{11}$ Respondents were excluded from the sample if they lived in nursing homes or had irregularities in their dementia classification (see discussion below), resulting in a sample consisting of 7,363 respondents. ${ }^{12}$ The NHATS collects data on individual demographics, and the variables used in this study include gender, race, marital status, education, and income. The NHATS also includes data on health, which the paper uses to create an index of major health conditions for each respondent using the self- or proxy-reported existence of a variety of chronic conditions and diseases. ${ }^{13}$ The multimorbidity index is the number of chronic conditions and diseases diagnosed by a doctor (heart attack, heart disease, high blood pressure, arthritis, osteoporosis, diabetes, lung disease, stroke, or cancer).

An important aspect of NHATS is the use of proxies to provide answers on behalf of sample respondents. ${ }^{14}$ For this study of financial assistance and dementia, proxies are particularly important because retirees can participate if they have or are developing dementia, when some may lack the capacity to respond to a survey. Thus, this study can examine how adaptations to declining cognitive functioning - especially the availability of financial assistance in the later-stages of dementia - affect well-being even when people lose the capacity to respond themselves.

This study proceeds in four steps. First, it identifies members of the sample who experience cognitive impairment or dementia. Second, it identifies their sources of assistance with financial management. Third, it identifies measures of financial and psychological well-

\footnotetext{
${ }^{11}$ The 2015 NHATS data were excluded from this analysis, because a large portion of the sample was refreshed that year, and this study relies on longitudinal trends to classify people with early or late-stage dementia.

12 NHATS tends to oversample older people and African-Americans. For more on NHATS sampling, see Montaquila et al. (2012).

${ }^{13}$ See Patel et al. (2014), Hunt et al. (2015), and Soones et al. (2016).

${ }^{14}$ Proxies were used if the sample respondents had dementia, illness, speech/hearing impairment, language barriers or were temporarily unavailable or deceased. In its regression analysis, the study controls for the proxy status of the respondent, in case proxies tend to respond differently than the respondents themselves.
} 
being, and finally estimates the relationship between these measures of well-being and assistance with finances.

\section{Identifying Cognitive Impairment and Dementia}

To identify respondents with cognitive impairment and dementia, this study relies on the methodology of Kasper et al. (2013). Recognizing that the NHATS (like most publicly available microeconomic data) does not contain medical diagnoses of dementia, Kasper et al. (2013) creates an algorithm using self-reported diagnoses of dementia, results of dementia screening interviews, and cognitive test scores to classify people as either having "no dementia," "possible dementia," or "probable dementia." While this method is well grounded in the literature, it is not without limitations. ${ }^{15}$ An indirect study of dementia may lead to a misidentification of the condition. To reduce the chance of incorrectly classifying people without dementia as having it, this study dropped participants from the analysis if their dementia classification improved over time. ${ }^{16}$ These cases were likely due to classification error since dementia is a degenerative disease.

Another limitation of the Kasper et al. approach with respect to this study is that it assigns a probability of dementia without necessarily measuring the severity. Since financial management help becomes increasingly important to prevent financial mistakes as dementia progresses, this study needs a way to measure the severity of dementia. To this end, this paper uses the longitudinal nature of the NHATS dataset to build on the Kasper et al. algorithm. Specifically, this paper classifies respondents as having no impairment, impairment, potential dementia, or established dementia based on the severity and frequency of their Kasper et al. classifications. ${ }^{17}$ Respondents are classified as not impaired if they had two or more years without dementia, with possible dementia, or with a combination of the two. Respondents are impaired, but without dementia, if they had possible dementia for three or more years.

Respondents have potential dementia if they had either possible or probable dementia in each of

\footnotetext{
${ }^{15}$ For more on limitations of NHATs dementia classification, see Kasper et al. (2013).

${ }^{16}$ This dropped 882 respondents from the sample.

${ }^{17}$ An ideal classification would group people as having early, intermediate, and late-stage dementia using criteria that are consistent with the corresponding clinical classifications for each stage. Unfortunately, the NHATS dataset does not provide the information necessary to use this ideal classification. As a result, those with "established dementia" in this study include a mix of individuals who could be classified as having late- or intermediate-stage dementia.
} 
the four survey years. Finally, respondents are classified as having established dementia if they had probable dementia for three or more consecutive years.

\section{Sources of Assistance for Financial Management and Other Activities}

To identify financial management help received by those with dementia, this paper examines the answers to questions on two topics: 1) how simple money matters were handled in the past month; and 2) whether respondents had any help with more complicated money matters in the past year. Simple money matters include writing checks, sending money orders or paying with cash, checking bank-balances, and making transfers, deposits or withdrawals from a bank or ATM. This paper classifies help with simple money matters in three ways: 1) received no help; 2) completed task together with someone; or 3) someone else carried out the task. If a respondent reports that they received help with their simple money matters, they are asked whether or not the help was received due to poor health or another degradation in their functional capacity (including deficits related to age, memory, vision, health condition/disease names, surgery, driving ability) or due to some other reason. If a respondent faced a less common money matter in the past year - for example, opening, closing, or cashing in certificates of deposits, checking and managing money market or retirement accounts, or applying for loans they were simply asked if anyone helped them with these, and if so, who.

Although the focus of the paper is on financial management, controlling for the availability of informal assistance with other types of daily activities is also important, because the study attempts to distinguish the effects of financial help from other factors that might improve well-being. To assess the overall level of care received by dementia patients, this paper creates a dependency index for Activities of Daily Living (ADL) and Instrumental Activities of Daily Living (IADL). ${ }^{18}$ The ADL index is the sum of assistance needed to bathe/shower, eat, dress, and go to the toilet, as well as assistance with basic mobility indoors and outdoors. ${ }^{19}$ The IADL index is the sum of assistance needed to shop for groceries, cook hot meals, do laundry, and manage finances. This study also creates a measure of size of each respondents' care network, which is the number of unique helpers who assist with mobility, driving and transportation, household activities, self-care activities, and medical care activities. ${ }^{20}$ Within the

\footnotetext{
${ }^{18}$ See Stern et al. (1994) or Örjan et al. (2016).

${ }^{19}$ See Lin (2014).

${ }^{20}$ See Andersson and Monin (2017).
} 
total care network, this study also identifies the total number of relatives and non-relatives providing care in case the quality of care differs between the two.

\section{Measuring Well-being}

This project measures two types of well-being: financial and psychological. Financial well-being is captured through the presence of food insecurity and measures of financial hardship. This study assesses food insecurity by whether respondents had skipped meals in the past month because they did not have enough money to buy food. Financial hardship is measured by whether survey participants reported instances in the past year of not having enough money to pay the rent/mortgage, utility bills, or medical/prescription drug bills.

To identify psychological well-being, the study uses the Generalized Anxiety Disorder scale-2 (GAD-2), which is part of the NHATS survey. Respondents to GAD-2 reported how often over the past month they felt nervous, anxious, or on edge, and if they had been unable to stop or control worrying. ${ }^{21}$ This study did not use other NHATS measures of psychological well-being like feelings of autonomy, because these questions were not asked of the proxy respondents, who make up a substantial part of the sample that have dementia.

\section{Results}

The goal of the study is to identify what share of those with dementia have assistance in general and with their finances specifically and then to identify how that assistance (or lack thereof) affects their well-being.

\section{Dementia and Caregiving}

About 21 percent of person-year observations in the sample have either potential or established dementia, with 7 percent having established dementia. Figure 1 shows that older members of the sample, as expected, are much more likely to have dementia than younger ones. For observations between ages 65 and 69, just 3 percent have established dementia, with the number increasing to over 25 percent for observations in their 80s. In addition to the vulnerability inherent in having dementia, Table 1 shows that those with dementia are generally

\footnotetext{
${ }^{21}$ See Appendix for the specification used in the study.
} 
more economically vulnerable: they are more likely to earn less than $\$ 25,000$ per year, less likely to have a high school degree, more likely to be a woman, and more likely to be widowed.

As dementia develops, individuals require more and more assistance. Figure 2 shows that by the time people have established dementia, they need help with 2.3 ADLS - basic activities like using the toilet or eating - and 2.3 IADLS - activities like grocery shopping and laundry. Indeed, 50 percent of those with established dementia need assistance to carry out three or more IADLs. Formal and informal caregivers are instrumental in providing help with these daily activities, with one to two caregivers typically providing care for a person with dementia. As Figure 3 shows, as dementia progresses, and the caregiving need increases and so does the size of the network providing care.

Traditionally, women have held greater responsibilities than men in caring for the elderly, and this trend is reflected in this study. ${ }^{22}$ As Figure 4 shows, close kin - spouses and children serve as the backbone of the caregiving network, but the composition of the network appears to change as dementia progresses. As it progresses, spouses were replaced by children, particularly daughters. The caregiving network provides help with a range of activities including mobility, driving and transportation, and household, self-care, and medical activities. ${ }^{23}$ But while these sources of care are all important, this study is specifically interested in whether this caregiving network helps with financial matters.

\section{To What Extent Do Caregivers Help Manage Money, and Who Provides the Help?}

The previous section showed that care networks grow considerably as people move from no cognitive impairment to established dementia. But while these individuals clearly have help with care generally, a diagnosis of dementia comes with a social disenfranchisement that might make them resistant to a change in their role identities until after they experience difficulties with their finances ${ }^{24}$ - in other words, when it is too late. Fortunately, as Figure 5 and 6 shows, over 85 percent of those with established dementia receive some form of help with both simple and complicated money matters (should they have them).

As with other types of assistance, Figure 7 shows that spouses and daughters provide assistance with finances in most cases, and relatives are the ones providing help in almost all

\footnotetext{
22 See Bookman and Kimbrel (2011) or Riffin et al. (2017).

23 See Andersson and Monin (2017); Riffin et al. ( 2017).

${ }^{24}$ See Beard and Fox (2008).
} 
cases. But as people progress through the stages of dementia, spouses become less involved in managing money and children become much more involved. Across all activities for daily living and financial management, Figure 8 shows that daughters continued to play a larger role than sons in providing help for people with established dementia. So the good news is that people with established dementia clearly have help available with their finances. This finding is especially important given Belbase and Sanzenbacher’s (2016) finding that most do not use a representative payee. A remaining question is how well that financial assistance works.

\section{To What Extent Does Help Managing Money Affect Well-Being?}

At a descriptive level, help managing finances appears to be positively correlated with the financial well-being of people with established dementia. Figures 9 and 10 show that if people with dementia get help with their finances, they look just like those without cognitive impairment in terms of their ability to pay for food, rent, utilities, and medicine. On the other hand, if people with established dementia do not get help managing their finances, they appear to suffer financially. In some cases, the differences are stark. For example, about 3 percent of people without impairment have trouble paying their utility bills. This increases to over 6 percent for those with established dementia and no help. But the share goes back down to 3 percent for those with established dementia who have a source of financial management assistance. Still, it is easy to imagine scenarios where that improvement has nothing to do with the help itself, but rather the characteristics of those receiving the help. For example, if those with access to financial management assistance are more educated, then the result shown in Figures 9 and 10 may simply be reflecting their education levels.

To investigate this issue further, we conducted a regression analysis, controlling for these other factors, to examine the effect on financial well-being of having assistance. The regression takes the following form:

$$
f_{i, t}=\beta_{0}+\beta_{1} \text { Dem }_{i, t}+\beta_{2} * \text { Assist }_{i, t}+\beta_{3} \text { Dem }_{i, t} * \text { Assist }_{i, t}+X_{i, t} \gamma+\varepsilon_{i, t}
$$

Where $f_{i, t}$ indicates that individual $i$ had trouble at time $t$ with at least one of the indicators of financial distress tabulated in Figures 9 and 10; Dem $_{i, t}$ indicates the individual has dementia; Assist $_{i, t}$ indicates they have assistance with simple or complicated money matters; 
and $X_{i, t}$ is a vector of individual-level controls. These individual-level controls include standard demographic variables like education, race, income, and age and a control for whether there was a proxy respondent. The control for a proxy is important in case proxies view the financial status of respondents differently than the respondent themselves. The coefficient $\beta_{1}$ indicates dementia's effect on well-being in the absence of assistance; $\beta_{2}$ is the effect of assistance on well-being in the absence of dementia; and $\beta_{3}$ is the effect of assistance on well-being for someone with dementia. The primary coefficient of interest is $\beta_{3}$, which can be interpreted as the relationship between assistance and well-being for those with dementia holding constant the other factors considered.

The results of this regression appear in Table 2. They show that people with established dementia who have no assistance are significantly worse off - being 7.1 percent more likely to have financial distress than those without dementia. But the table also shows that having dementia with assistance effectively offsets this with a reduction of 9.9 percent. Other coefficients have the expected signs, with lower income, less education, and minority status being associated with significantly higher rates of financial difficulty. One thing worth noting is that the regression included two controls for dementia, one for established dementia and one for potential dementia (for simplicity, equation (1) showed just one control for dementia). It seems the relationship between help and well-being exists only for people with established dementia. For people with potential dementia or only cognitive impairment, no clear relationships exist between receiving informal help and financial well-being. This may reflect that while those with established dementia need assistance regardless of their initial financial ability, those with potential dementia receive help only when they are trouble. Unfortunately, the regression cannot provide a definitive answer.

Regarding psychological outcomes, the paper runs the same regression reported in Table 2, but replaces the dependent variable with whether or not the person has anxiety. The same general pattern emerges in this regression, shown in Table 3. People with established dementia who have no assistance are 13.3 percent more likely to have anxiety, and again the effect seems to be somewhat offset if the individual has assistance, with a reduction of 8.0 percent. Financial assistance seems to be associated with improved outcomes both on the financial and psychological front. Although it is difficult to attribute these positive outcomes to the assistance itself even using regression analysis, the fact that the relationship holds up even given the use of 
controls suggests it is somewhat robust. Future research should attempt to establish a causal relationship between informal caregiving and financial well-being.

\section{Conclusion}

Social Security’s Representative Payee Program protects beneficiaries who lack the capacity to use their benefits in their own best interest. Most of the program's payees represent children, who require a guardian to manage their finances. But many recipients of old-age benefits who have dementia, especially late-stage dementia, also lack the capacity to handle their financial affairs, making them vulnerable to financial exploitation. ${ }^{25}$ Yet only 9 percent of people with dementia appear to use a representative payee. ${ }^{26}$ This paper suggests one logical explanation for this low usage: informal caregivers step in to manage finances in the same way that they help carry out a range of other daily activities. In this context, a person with established dementia may not need a payee if he or she lives with a spouse who has been handling the household finances or has an adult child who takes over, while a different person living alone with late stage dementia would plausibly benefit from a payee. These findings suggest that for most families, the representative payee program might need to serve only as a last resort (similar to legal guardianship) when help is either unavailable or not working. In most cases, however, family members appear to successfully negotiate control over their elderly family members' daily activities including finances.

\footnotetext{
${ }^{25}$ For decline in financial capacity see: Pérès et al. (2008) and Widera et al. (2011). For exploitation, see Peterson et al (2014).

${ }^{26}$ See: Belbase and Sanzenbacher (2016).
} 


\section{References}

Andersson, Matthew and Joan Monin. 2017. "Informal Care Networks in the Context of Multimorbidity: Size, Composition, and Associations with Recipient Psychological WellBeing.” Journal of Aging and Health 1-24.

Anguelov, Chris E., Gabriella Ravida, and Robert R. Weathers II. 2015. “Adult OASDI Beneficiaries and SSI Recipients Who Need Representative Payees: Projections for 2025 and 2035.” Social Security Bulletin 75(2): 1-17.

Beard, Renee and Patrick Fox. 2008. "Resisting Social Disenfranchisement: Negotiating Collective Identities and Everyday Life with Memory Loss.” Social Science and Medicine 66(7): 1509-1520.

Belbase, Anek and Geoffrey T. Sanzenbacher. 2016. “Cognitive Impairment and Social Security’s Representative Payee Program. Working Paper 2016-12. Chestnut Hill, MA: Center for Retirement Research at Boston College.

Berry, Brandon, Ester Carolina Apseoa-Varano, and Yarin Gomez. 2015. "How Family Members Manage Risk Around Functional Decline: the Autonomy Management Process in Households Facing Dementia.” Social Science \& Medicine 130: 107-114.

Bookman, Ann and Delia Kimbrel. 2011. "Families and Elder Care in the Twenty-First Century.” Future of Children 21(2): 117-140.

Herbert, Liesi E., Jennifer Weuve, Paul A. Scherr, and Denis A. Evans. 2013. “Alzheimer Disease in the United States (2010-2050) Estimated Using the 2010 Census.” Neurology 80(19): 1778-1783.

Hsu, Joanne W. and Robert Willis. 2013. "Dementia Risk and Financial Decision Making by Older Households: The Impact of Information.” Journal of Human Capital 7(4): 340377.

Hunt, Lauren J., Kenneth E. Covinsky, Kristine Yaffe, Caroline E. Stephens, Yinghui Miao, W. John Boscardin, and Alex K. Smith. 2015. "Pain in Community-Dwelling Older Adults with Dementia: Results from the National Health and Aging Trends Study.” Journal of American Geriatrics Society 63(8): 1503-1511.

Kasper, Judith D., Vicki A. Freedman, and Brenda Spillman. 2013. "Classification of Persons by Dementia Status in the National Health and Aging Trends Study.” Technical Paper \#5. Baltimore, MD: John Hopkins University School of Public Health.

Lin, I-Fen and Hsueh-Sheng Wu. 2014. “Activity Limitations, Use of Assistive Devices or Personal Help, and Well-Being: Variation by Education.” Journal of Gerontology 69B (Suppl_1): S16-S25. 
Martin, Roy C., Shannon M. Annis, Laurie Z. Darling, Virginia Wadley, Lindy Harrell, and Daniel C. Marson. 2003. "Loss of Calculation Abilitites in Patients with Mild and Moderate Alzheimer Disease.” Archives of Neurology 60(11): 1585-1589.

Montaquila, Jill, Vicki A. Freedman, Brad Edwards, and Judith D. Kasper. 2012. "National Health and Aging Trends Study Round 1 Sample Design and Selection.” NHATS Technical Paper \#1. Baltimore, MD: John Hopkins University School of Public Health.

Montaquila, Jill, Vicki A. Freedman, Judith D. Kasper. 2012. "National Health and Aging Trends Study Round 1 Income Imputation.” NHATS Technical Paper \#3. Baltimore, MD: John Hopkins University School of Public Health.

New York City Department for the Aging, Lifespan of Greater Rochester, Inc., and Weill Cornell Medical Center of Cornell. 2011. "Under the Radar: New York State Elder Abuse Prevalence Study.” Rensselaer, NY. Available at: http://ocfs.ny.gov/main/reports/Under\%20the\%20Radar\%2005\%2012\%2011\%20final\%2 Oreport.pdf

Office of the Inspector General. 2010. Aged Beneficiaries in Need of Representative Payees. Report No. A-09-09-29002. Washington, DC.

Örjan , Åkerborg, Andrea Lang, Anders Wimo, Anders Sköldunger, Laura Fratiglioni, Maren Gaudig, and Mats Rosenlund. 2016. "Cost of Dementia and Its Correlation with Dependence.” Journal of Aging and Health. 28(8): 1448-1464.

Patel, Kushang V., Elizabeth A. Phelan, Suzanne G. Leveille, Sarah E. Lamb, Celestin Missikpode, Robert B. Wallace, Jack M. Guralnik, and Dennis C. Turk. 2014. "High Prevalence of Falls, Fear of Falling, and Impaired Balance in Older Adults with Pain in the United States: Findings from the 2011 National Health and Aging Trends Study" Journal of the American Geriatrics Society 62(10): 1844-1852.

Pérès Catherine Helmer, Hélène Amieva, Jean-Marc Orgogozo, Isabelle Rouch, Jean-François Dartigues, and Pascale Barberger-Gateau. 2008. "Natural History of Decline in Instrumental Activities of Daily Living Performance over the 10 Years Preceding the Clinical Diagnosis of Dementia: A Prospective Population-Based Study” Journal of American Gerontology 56: 37-44.

Peterson, Janey C., David PR Burnes, Paul L. Caccamise, Art Mason, Charles R. Henderson, Martin T. Wells, Jacquelin Berman et al. 2014. "Financial Exploitation of Older Adults: A Population-Based Prevalence Study.” Journal of General Internal Medicine 29(12): $1615-1623$.

Riffin, Catherine, Peter Van Neww, Jennifer Wolff, and Terri Fired. 2017. "Family and Other Unpaid Caregivers and Older Adults with and without Dementia and Disability” Journal of the American Geriatrics Society (e-publication - print version forthcoming). 
Soones, Tacara, Alex Federman, Bruce Leff, Albert Siu, and Katherine Ornstein. 2016. “TwoYear Mortality in Homebound Older Adults: An Analysis of the National Health and Aging Trends Study” Journal of the American Geriatrics Society 65(1): 123-129.

Stern, Yaakov, Steven M. Albert Mary Sano, Marcus Richards, Lisa Miller, Marshal Folstein, Marilyn Albert, Frederick W. Bylsma, and Ginette Lafelche. 1994. "Assessing Patient Dependence in Alzheimer’s Disease.” Journal of Gerontology 49(5): 216-222.

Triebel, K.L., R. Martin, H.R. Griffith, J. Marceaux, O.C. Okonkwo, L. Harrell, D. Clark, J. Brockington, A. Bartolucci, and D.C. Marson. 2009. "Declining Financial Capacity in Mild Cognitive Impairment: A 1-year Longitudinal Study.” Neurology 73(12): 298-234.

Widera, Eric, Veronika Steenpass, Daniel Marson. 2011. "Finances in the Older Patient With Cognitive Impairment: ‘He Didn’t Want Me to Take Over.' ” JAMA 305(7): 698-706. 
Figure 1. Share of Sample with Potential or Established Dementia, by Age

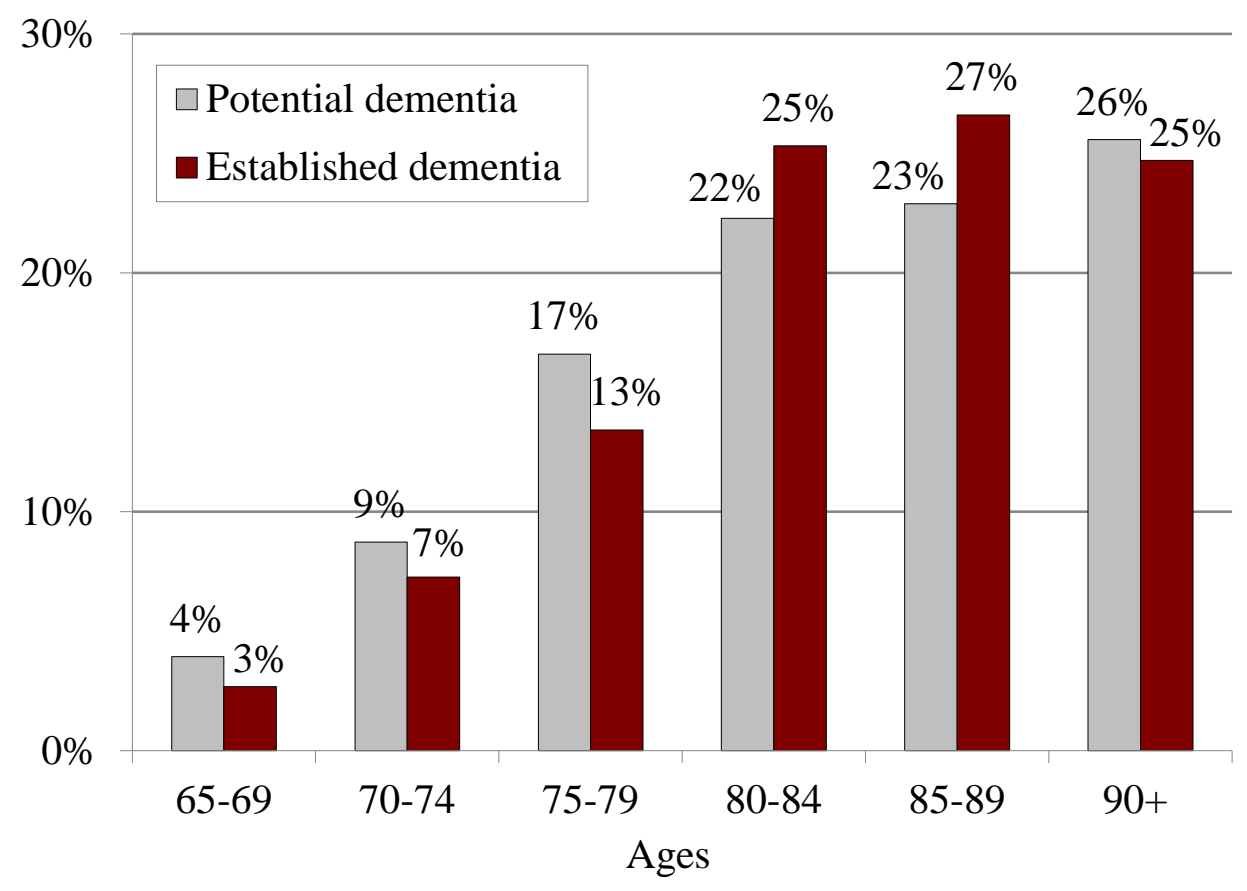

Source: Authors' calculation from the NHATS, 2011-2014.

Figure 2. Average Number of Assisted ADLs and IADLs, by Dementia Status

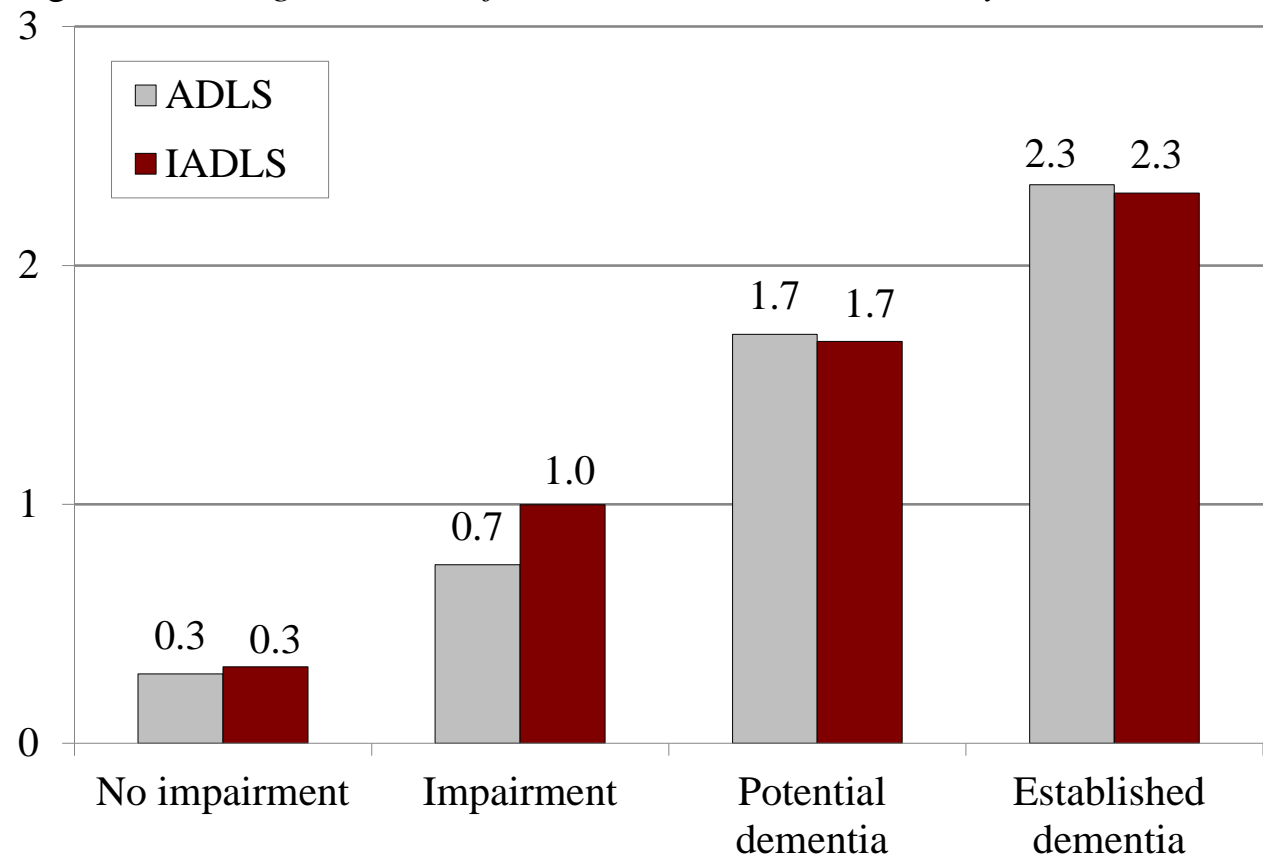

Source: Authors' calculation from the NHATS, 2011-2014. 
Figure 3. Average Number of People Providing Some Assistance, by Dementia Status

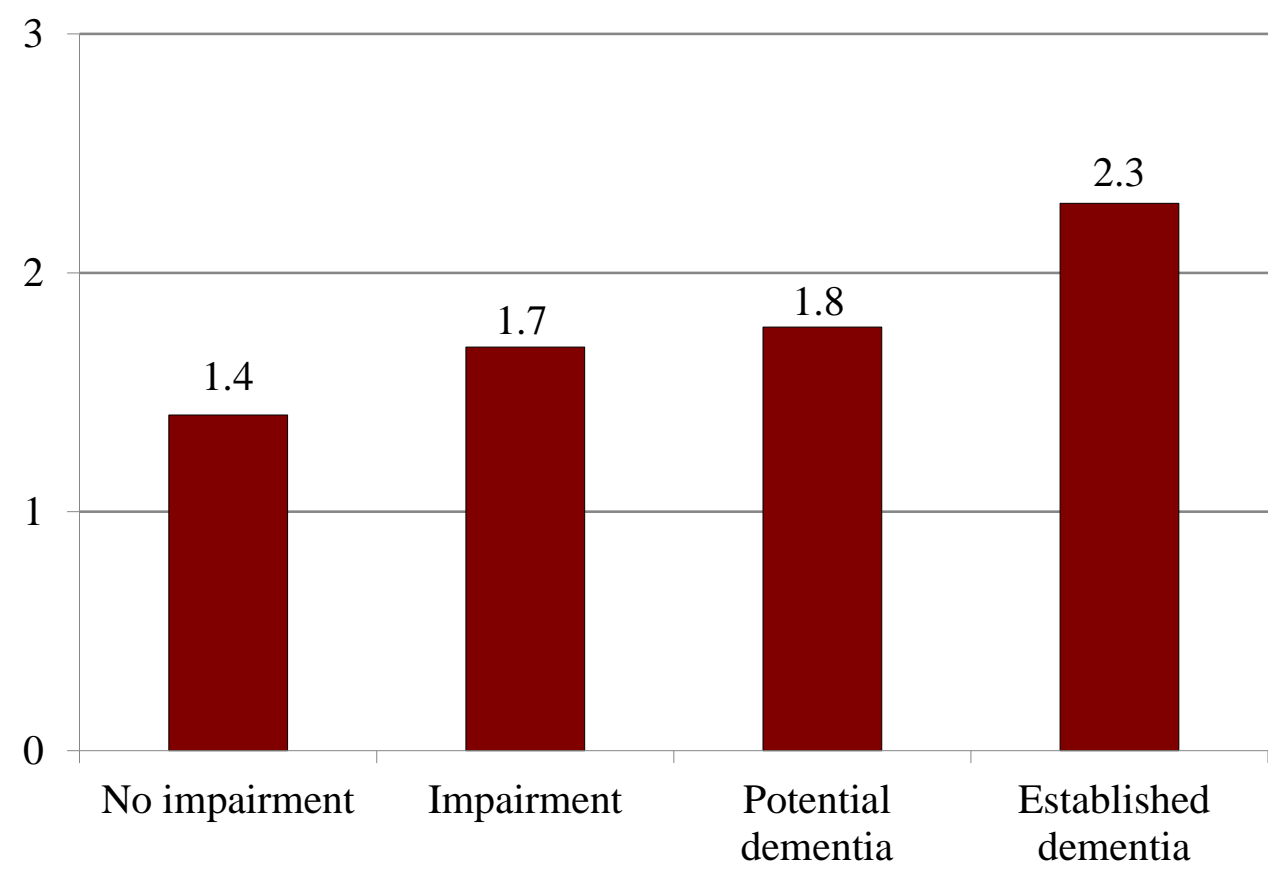

Source: Authors' calculation from the NHATS, 2011-2014.

Figure 4. Composition of Care Network

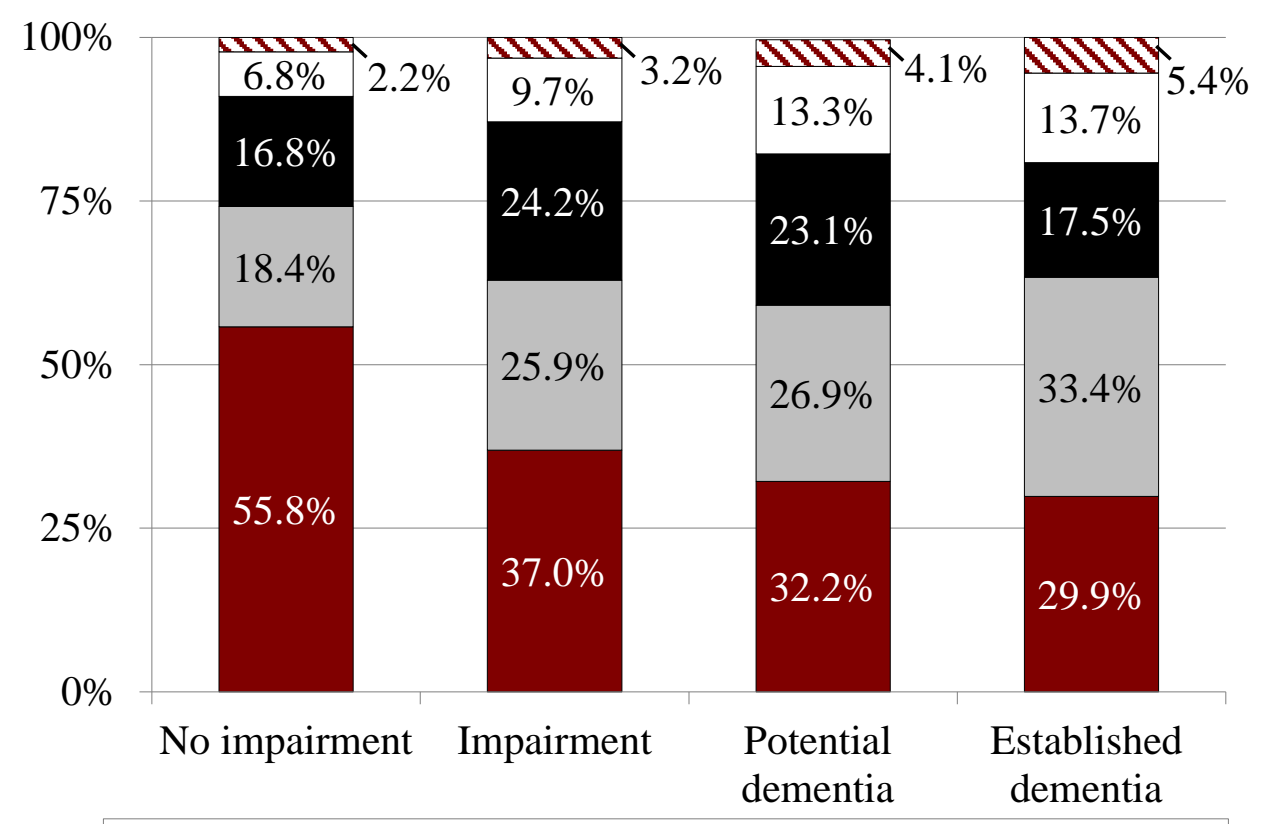

- Spouse $\square$ Daughter $\boldsymbol{\square}$ Son $\square$ Other relative $\mathbf{\Delta}$ Other nonrelative

Source: Authors' calculation from the NHATS, 2011-2014. 
Figure 5. Share with Established Dementia Who Have Simple Banking Matters and Receive Help

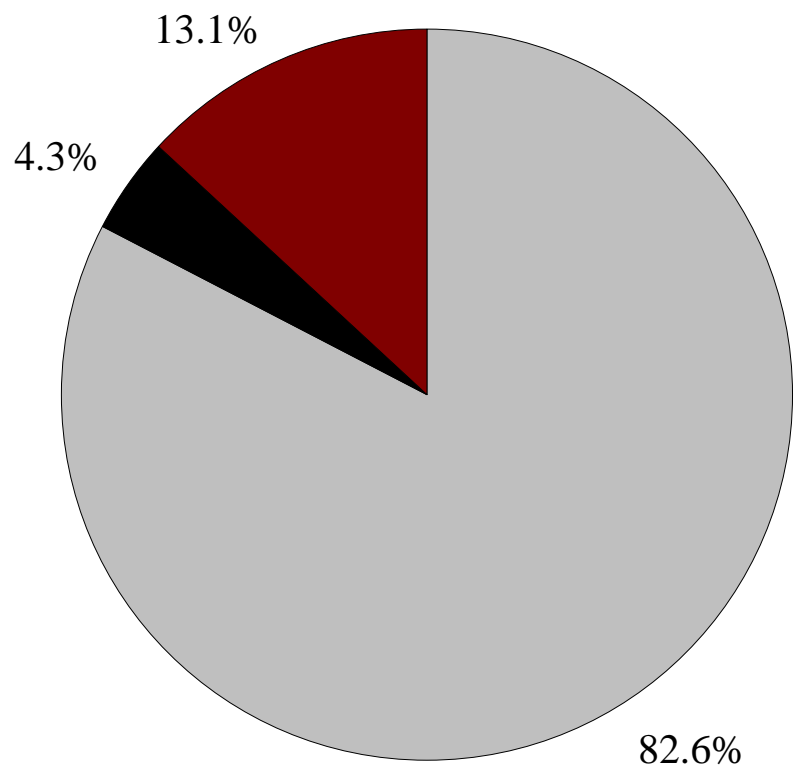

$\square$ Received help $\quad$ Sometimes received help $\quad \square$ Did not receive help

Source: Authors’ calculation from the NHATS, 2011-2014.

Figure 6. Share with Established Dementia Who Have Complicated Banking Matters and Receive Help

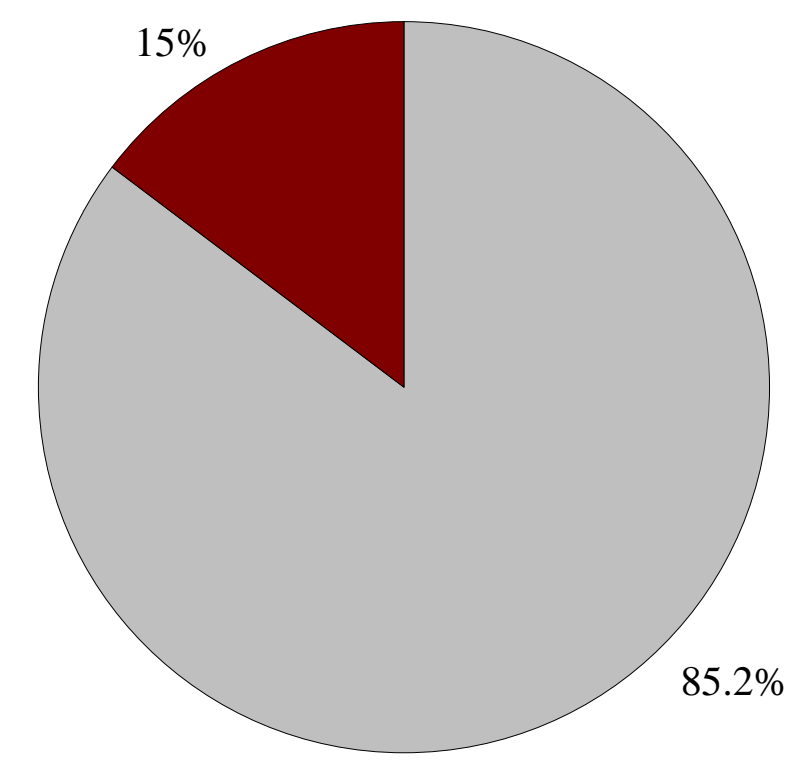

$\square$ Received help $\quad \square$ Did not receive help

Note: For complicated money matters, individuals were only asked if they had help or not and not the frequency of the help.

Source: Authors' calculation from the NHATS, 2011-2014. 
Figure 7. Share Helping with Simple Money Matters, by Relationship

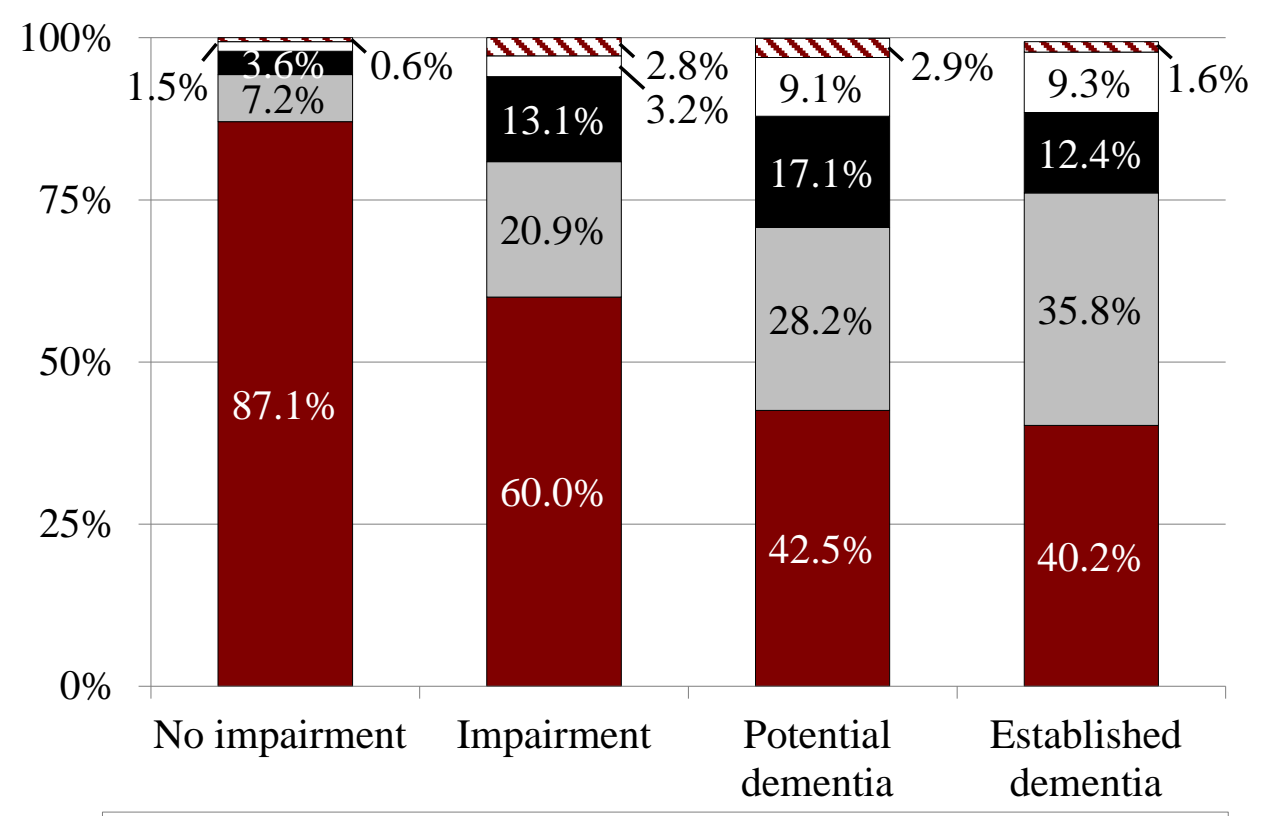

— Spouse $\square$ Daughter $\square$ Son $\square$ Other relative s Other nonrelative

Source: Authors' calculation from the NHATS, 2011-2014.

Figure 8. Share of Assistance Coming from Daughters and Sons

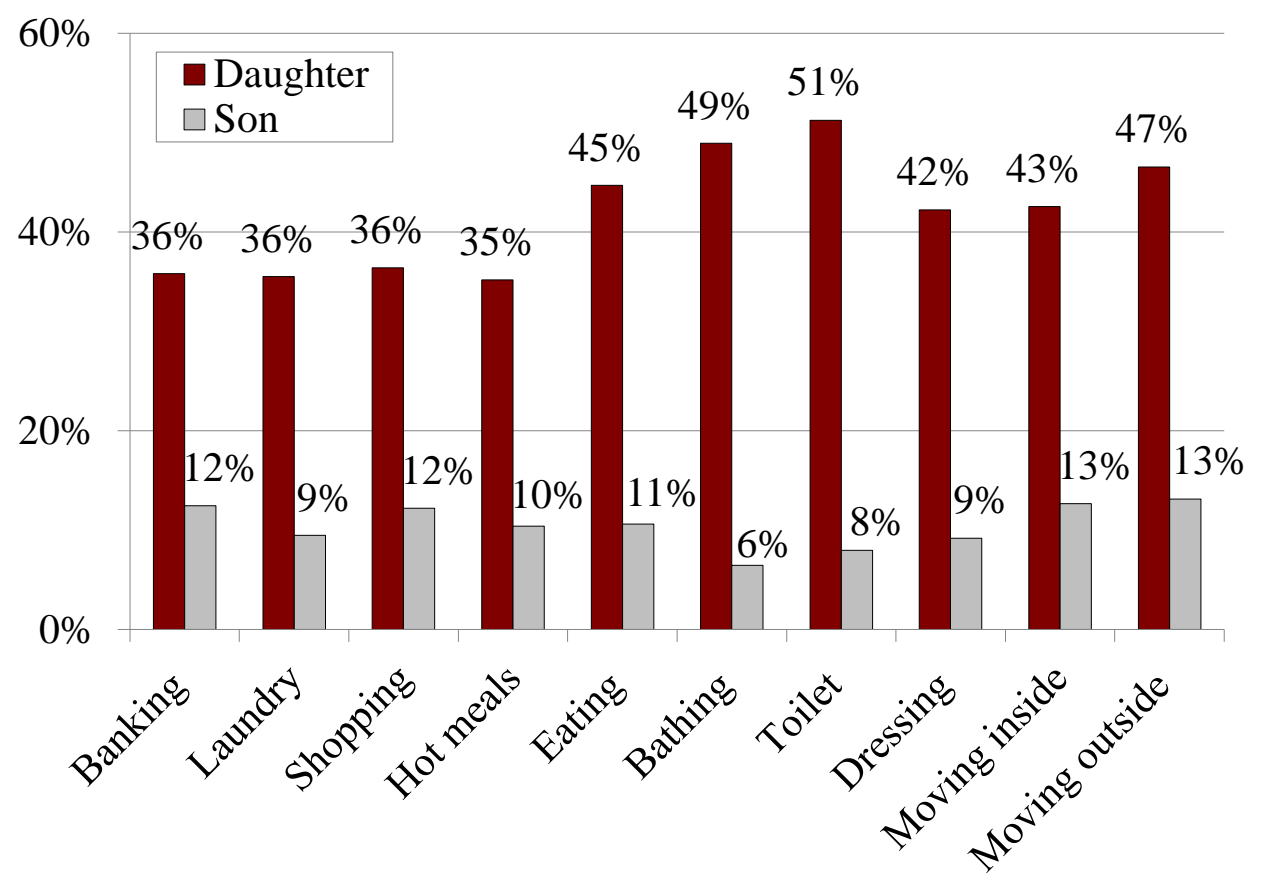

Source: Authors' calculation from the NHATS, 2011-2014. 
Figure 9. Share of People with Financial Problems and Presence of Help with Simple Money Matters, by Impairment Status

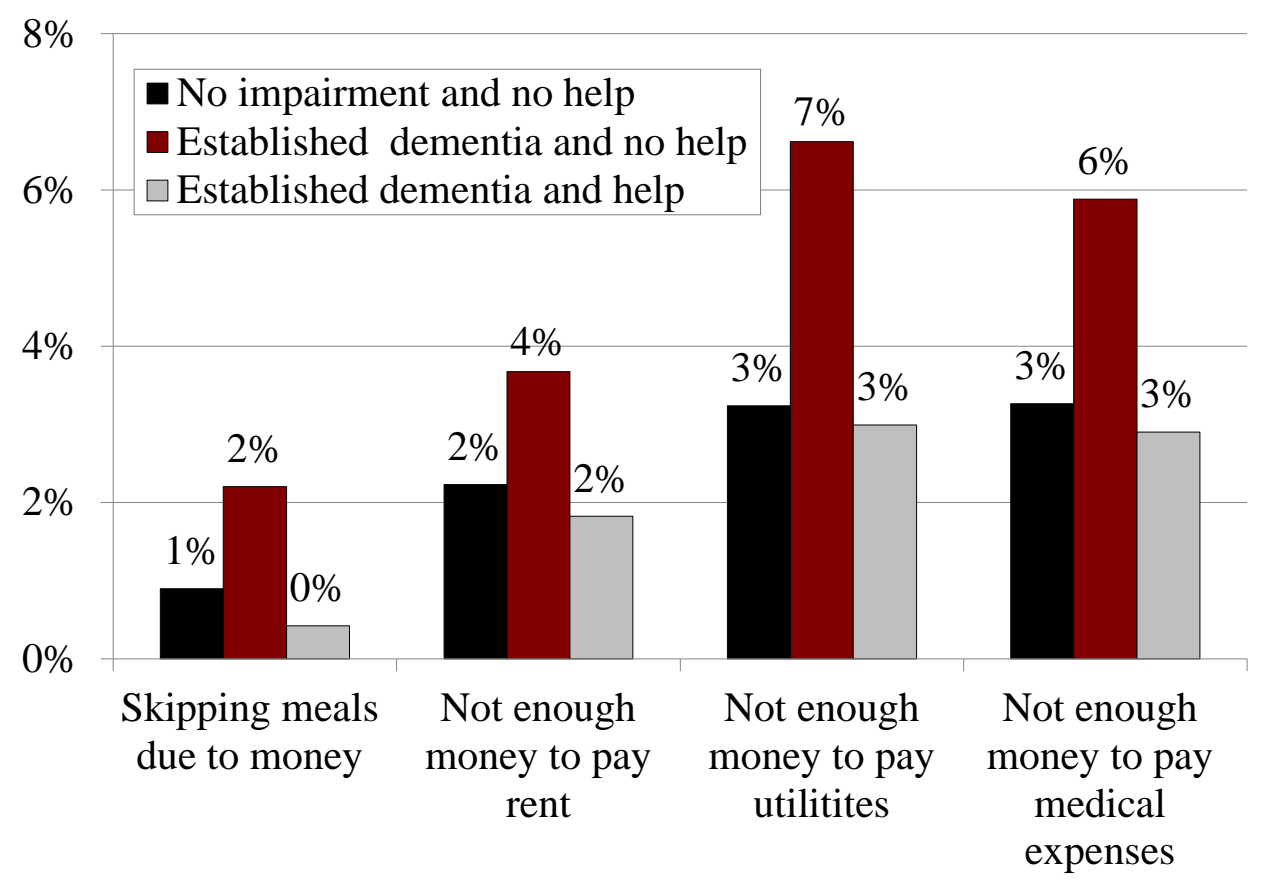

Source: Authors' calculation from the NHATS, 2011-2014.

Figure 10. Share of People with Financial Problems and Presence of Help with Complex Money Matters, by Impairment Status

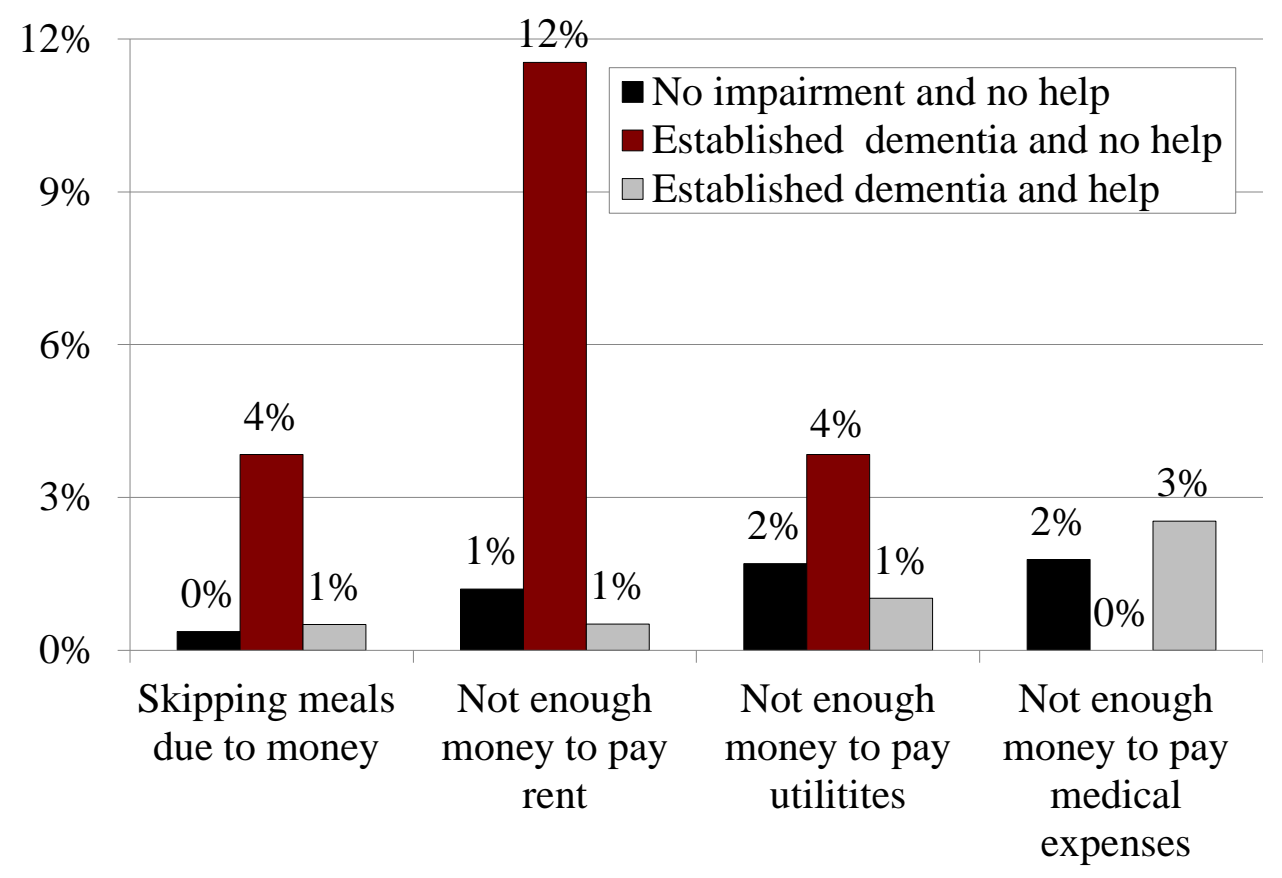

Source: Authors’ calculation from the NHATS, 2011-2014. 
Table 1. Demographics by Cognitive Functioning

\begin{tabular}{lcccc}
\hline Demographic & No impairment & Impairment & $\begin{array}{r}\text { Potential } \\
\text { dementia }\end{array}$ & $\begin{array}{r}\text { Established } \\
\text { dementia }\end{array}$ \\
\hline $\begin{array}{l}\text { Gender } \\
\quad \text { Female }\end{array}$ & $58 \%$ & $56 \%$ & $62 \%$ & $62 \%$ \\
$\begin{array}{l}\text { Race } \\
\quad \text { White }\end{array}$ & 73 & 59 & 59 & 57 \\
$\quad$ Black & 19 & 25 & 27 & 28 \\
$\quad$ Hispanic & 4 & 9 & 10 & 10 \\
$\quad$ Other & 2 & 5 & 3 & 4 \\
Marital status & & & & \\
$\quad$ Married/ living with partner & 55 & 44 & 34 & 36 \\
$\quad$ Widowed & 28 & 40 & 50 & 48 \\
$\quad$ Single & 16 & 16 & 16 & 16 \\
Education & & & & \\
$\quad$ Less than high school & 19 & 42 & 44 & 48 \\
$\quad$ High school & 36 & 29 & 32 & 26 \\
$\quad$ Some college & 14 & 10 & 7 & 9 \\
$\quad$ College & 29 & 17 & 15 & 15 \\
$\quad$ Refused & 1 & 1 & 2 & 3 \\
Income & & & & \\
$\quad<25,000$ & 47 & 51 & 60 & 75 \\
$\quad$ \$25,000-\$99,999 & 33 & 24 & 18 & 23 \\
$\quad>$ \$100,000 & 20 & 25 & 22 & 3 \\
\hline Average number of chronic illness & 2.4 & 2.6 & 2.7 & 2.7 \\
\hline
\end{tabular}

Source: Authors' calculation from the NHATS, 2011-2014. 
Table 2. Marginal Effects of Assistance with Financial Management on Financial Hardship

\begin{tabular}{|c|c|}
\hline & Experiences financial hardship \\
\hline Established dementia and financial help & $\begin{array}{l}-0.099 * * \\
(-0.039)\end{array}$ \\
\hline Established dementia & $\begin{array}{c}0.071 * \\
(-0.037)\end{array}$ \\
\hline Age 90+ & $\begin{array}{l}-0.062 * * * \\
(-0.13)\end{array}$ \\
\hline White & $\begin{array}{l}-0.055 * * \\
(-0.027)\end{array}$ \\
\hline Age 85-89 & $\begin{array}{l}-0.05^{* * *} \\
(-0.012)\end{array}$ \\
\hline Proxy & $\begin{array}{l}-0.044 * * * \\
(-0.014)\end{array}$ \\
\hline Age $80-84$ & $\begin{array}{l}-0.04 * * * \\
(-0.011)\end{array}$ \\
\hline Income & $\begin{array}{l}-0.03^{* * *} \\
(-0.004)\end{array}$ \\
\hline Age 75-79 & $\begin{array}{l}-0.028 * * \\
(-0.011)\end{array}$ \\
\hline Lives in metropolitan area & $\begin{array}{c}0.016 * * \\
(-0.007)\end{array}$ \\
\hline Number of chronic illnesses & $\begin{array}{l}0.009 * * * \\
(-0.002)\end{array}$ \\
\hline Number of ADL dependency & $\begin{array}{c}0.008 * * \\
(-0.004)\end{array}$ \\
\hline Potential dementia and financial help & $\begin{array}{r}0.025 \\
(-0.022)\end{array}$ \\
\hline Financial help & $\begin{array}{r}0.009 \\
(-0.007)\end{array}$ \\
\hline Potential dementia & $\begin{array}{r}0.006 \\
(-0.014)\end{array}$ \\
\hline Hispanic & $\begin{array}{r}0.006 \\
(-0.033)\end{array}$ \\
\hline Number of IADL dependency & $\begin{array}{r}0.005 \\
(-0.004)\end{array}$ \\
\hline Black & $\begin{array}{r}0.005 \\
(-0.028)\end{array}$ \\
\hline Age $70-74$ & $\begin{array}{r}0.005 \\
(-0.011)\end{array}$ \\
\hline
\end{tabular}


Table 2. Marginal Effects of Assistance with Financial Management on Financial Hardship (cont'd)

\begin{tabular}{lc}
\hline & Experiences financial hardship \\
\hline \multirow{2}{*}{ Male } & -0.004 \\
& $(-0.006)$ \\
College & -0.009 \\
& $(-0.006)$ \\
Coupled & -0.009 \\
& $(-0.011)$ \\
Widowed & -0.011 \\
& N \\
R-squared & $(-0.011)$ \\
\hline
\end{tabular}

Notes: ${ }^{*} \mathrm{p}<0.10,{ }^{* *} \mathrm{p}<0.05,{ }^{* * *} \mathrm{p}<.01$. Robust standard errors in parentheses.

Source: Authors' calculation from the NHATS, 2011-2014. 
Table 3. Marginal Effects of Assistance with Financial Management on Anxiety

\begin{tabular}{|c|c|}
\hline & Has anxiety \\
\hline Established dementia & $\begin{array}{c}0.133^{* * *} \\
(-0.036)\end{array}$ \\
\hline Established dementia and financial help & $\begin{array}{c}-0.08^{* *} \\
(-0.039)\end{array}$ \\
\hline Potential dementia & $\begin{array}{c}0.063 * * * \\
(-0.017)\end{array}$ \\
\hline Age 90+ & $\begin{array}{l}-0.061 * * * \\
(-0.014)\end{array}$ \\
\hline Black & $\begin{array}{c}-0.039 * \\
(-0.022)\end{array}$ \\
\hline College & $\begin{array}{l}-0.035^{* * *} \\
(-0.007)\end{array}$ \\
\hline Number of IADL dependency & $\begin{array}{c}0.032 * * * \\
(-0.004)\end{array}$ \\
\hline Age 85-90 & $\begin{array}{c}-0.028^{* *} \\
(-0.012)\end{array}$ \\
\hline Number of ADL dependency & $\begin{array}{c}0.024 * * * \\
(-0.004)\end{array}$ \\
\hline Number of chronic illnesses & $\begin{array}{c}0.024 * * * \\
(-0.002)\end{array}$ \\
\hline Age 80-84 & $\begin{array}{l}-0.021 * * \\
(-0.01)\end{array}$ \\
\hline Male & $\begin{array}{c}-0.02 * * * \\
(-0.007)\end{array}$ \\
\hline Income & $\begin{array}{l}-0.016^{* * *} \\
(-0.004)\end{array}$ \\
\hline Age 75-79 & $\begin{array}{l}-0.016 * \\
(-0.01)\end{array}$ \\
\hline Financial help & $\begin{array}{c}-0.015^{* *} \\
(-0.007)\end{array}$ \\
\hline Age 70-74 & $\begin{array}{c}-0.015 * \\
(-0.009)\end{array}$ \\
\hline Hispanic & $\begin{array}{r}0.022 \\
(-0.026)\end{array}$ \\
\hline Lives in Metropolitan area & $\begin{array}{r}0.001 \\
(-0.008)\end{array}$ \\
\hline Proxy & $\begin{array}{r}0.001 \\
(-0.019)\end{array}$ \\
\hline
\end{tabular}


Table 3. Marginal Effects of Assistance with Financial Management on Anxiety (cont'd)

\begin{tabular}{lc}
\hline & Has anxiety \\
\hline \multirow{2}{*}{ Coupled } & -0.001 \\
& $(-0.01)$ \\
Widowed & -0.01 \\
& $(-0.011)$ \\
Potential dementia and financial help & -0.011 \\
& $(-0.023)$ \\
White & -0.021 \\
& $(-0.021)$ \\
\hline R-squared & 14,916 \\
\hline
\end{tabular}

Notes: ${ }^{*} \mathrm{p}<0.10,{ }^{* *} \mathrm{p}<0.05,{ }^{* * *} \mathrm{p}<.01$. Robust standard errors in parentheses.

Source: Authors' calculation from the NHATS, 2011-2014. 


\section{Appendix}

Table A1. Specification of Demographic Variables

\begin{tabular}{|c|c|}
\hline Variable & Specification \\
\hline Race & $\begin{array}{l}\text { White, Black, Hispanic, Other (Asian, American Indian, Native } \\
\text { Hawaiian) }\end{array}$ \\
\hline Marital status & Married/living with a partner, widowed, single \\
\hline Education & Less than high school, high school, some college, college \\
\hline$\overline{\text { Age }}$ & $65-69,70-74,75-79,80-84,85-89,90+$ \\
\hline Income $^{27}$ & Less than $\$ 25,000, \$ 25,000-\$ 9,999$, and more than $\$ 100,000$ \\
\hline Anxiety & $\begin{array}{l}\text { Response categories for the two questions included: not at all, } \\
\text { several days, more than half the days, and nearly every day. Scores } \\
\text { were summed for each measure }(0=\text { not at all; } 1=\text { several days; } \\
2=\text { more than half the days; } 3=\text { nearly every day). A score of three or } \\
\text { greater signified anxiety }\end{array}$ \\
\hline $\begin{array}{l}\text { Activities for Daily Living } \\
\text { Index }\end{array}$ & $\begin{array}{l}\text { the sum of assistance needed for bathing/showering, dressing, going } \\
\text { to the toilet, basic mobility inside and outside, and eating }\end{array}$ \\
\hline $\begin{array}{l}\text { Instrumental activities for } \\
\text { Daily Living Index }\end{array}$ & $\begin{array}{l}\text { the sum of assistance needed for shopping for groceries, cooking } \\
\text { hot meals, laundry, and managing finances }\end{array}$ \\
\hline Multi-morbidity Index & $\begin{array}{l}\text { Number of chronic conditions and diseases diagnosed by doctor } \\
\text { (heart attack, heart disease, high blood pressure, arthritis, } \\
\text { osteoporosis, diabetes, lung disease, stroke, or cancer) }\end{array}$ \\
\hline Visit friends & $\begin{array}{l}\text { Whether or not respondent had visited family or friends in last } \\
\text { month }\end{array}$ \\
\hline Attend religious service & $\begin{array}{l}\text { Whether or not respondent had attended religious service in last } \\
\text { month }\end{array}$ \\
\hline Other people in household & If there are more people in household beside respondent and spouse \\
\hline Has daughter or son & Binary variables of whether respondent has son or daughter \\
\hline Sense of Community Index & $\begin{array}{l}\text { Sum of scores (1-3) of how well people know each other, people are } \\
\text { willing to help in community, and if sample respondent trusts } \\
\text { people in their community. Final index is 3-9 with higher scores } \\
\text { indicating greater sense of community. }\end{array}$ \\
\hline
\end{tabular}

${ }^{27}$ Income is the log of respondent's reported total income and imputed values of total income (Montaquila et al. 2012). 


\section{RECENT WORKING PAPERS FROM THE CENTER FOR RETIREMENT RESEARCH AT BOSTON COLLEGE}

The Behavioral and Consumption Effects of Social Security Changes Wenliang Hou and Geoffrey T. Sanzenbacher, September 2017

Family Transfers With Retirement-Aged Adults in the United States: Kin Availability, Wealth Differentials, Geographic Proximity, Gender, and Racial Disparities Ashton M. Verdery, Jonathan Daw, Colin Campbell, and Rachel Margolis, August 2017

Guardianship and the Representative Payee Program

Anek Belbase and Geoffrey T. Sanzenbacher, August 2017

The Relative Effects of Economic and Non-Economic Factors on Taxpayers' Preferences Between Front-Loaded and Back-Loaded Retirement Savings Plans Andrew D. Cuccia, Marcus M. Doxey, and Shane R. Stinson, July 2017

Social Security and Total Replacement Rates in Disability and Retirement Mashfiqur R. Khan, Matthew S. Rutledge, and Geoffrey T. Sanzenbacher, May 2017

An Experimental Analysis of Modifications to the Survivor Benefit Information within the Social Security Statement

Jeffrey Diebold and Susan Camilleri, May 2017

Actuarial Inputs and the Valuation of Public Pension Liabilities and Contribution Requirements: A Simulation Approach

Gang Chen and David S. T. Matkin, May 2017

Why Are U.S. Households Claiming Social Security Later?

Wenliang Hou, Alicia H. Munnell, Geoffrey T. Sanzenbacher, and Yinji Li, April 2017

Rising Inequality in Life Expectancy by Socioeconomic Status

Geoffrey T. Sanzenbacher, Anthony Webb, Candace M. Cosgrove, and Natalia S. Orlova, April 2017

The Effect of Job Mobility on Retirement Timing by Education

Geoffrey T. Sanzenbacher, Steven A. Sass, and Christopher M. Gillis, February 2017

Would Reducing the Price of Employing an Older Worker Improve Labor Market Outcomes by Socioeconomic Status? Evidence from Health Insurance Premium Restrictions

Matthew S. Rutledge and Caroline V. Crawford, December 2016

All working papers are available on the Center for Retirement Research website (http://crr.bc.edu) and can be requested by e-mail (crr@bc.edu) or phone (617-552-1762). 